\title{
Electrical and spectroelectrochemical investigation of thiophene-based donor-acceptor copolymers with 3,4-ethylenedioxythiophene
}

\author{
Marcus Henrique de Araujo', Tulio Matencio', Claudio Luis Donnici¹ and Hállen Daniel Rezende Calado1,2* \\ 'Departamento de Química, Universidade Federal de Minas Gerais - UFMG, Belo Horizonte, MG, Brasil \\ ${ }^{2}$ Centro de Tecnologia de Nanomateriais e Grafeno - CTNano, Belo Horizonte, MG, Brasil \\ *hallendaniel@ufmg.br
}

\begin{abstract}
This work reports the spectroelectrochemical and electrical behavior of electropolymerized donor-acceptor like (D-A) copolymer films, based on 3,4-ethylenedioxythiophene (EDOT) and beta-substituted electron-acceptor thiophenes. Initially, the copolymer films were deposited on indium tin oxide substrates, which spectroelectrochemistry measurements were carried out with an UV-Vis spectrophotometer. Hence, it was possible to observe the electrochromic properties of these materials, visualizing the color changing towards different potentials applied. The experiments have shown that these D-A like copolymers presented good electrochromic properties, such as optical contrast, coloration efficiency, and switching times. Additionally, films prepared on a platinum working electrode were investigated by electrochemical impedance spectroscopy, which has shown the electrical behavior of those copolymers and their potential as candidates to capacitive devices building. Therefore, the combination of electron-donor EDOT with those electron-acceptor monomers is indeed a useful strategy to tailoring and fine-tuning the physicochemical properties of polythiophenes with innovative applications.
\end{abstract}

Keywords: donor-acceptor copolymers, electrical behavior, polythiophenes, spectroelectrochemistry.

How to cite: Araujo, M. H., Matencio, T., Donnici, C. L., \& Calado, H. D. R. (2020). Electrical and Spectroelectrochemical investigation of thiophene-based donor-acceptor copolymers with 3,4-ethylenedioxythiophene. Polimeros: Ciência e Tecnologia, 30(1), e2020001. https://doi.org/10.1590/0104-1428.03519

\section{Introduction}

The polythiophene semiconductor materials have been massively studied for applications as active layer in organic-electronic devices ${ }^{[1,2]}$, and their derivatives have booth environmental and thermic stability, as well good optoelectronic properties, allowing the uses in electrochromic devices $^{[3-6]}$, organic photovoltaic devices ${ }^{[7-9]}$, solar cells ${ }^{[10-12]}$, organic light-emitting diodes ${ }^{[13-15]}$, rechargeable batteries ${ }^{[16-19]}$, among several others. Recently, conducting polymers have also been applied on the design of soft actuators and bioelectronic interfaces ${ }^{[20,21]}$, e.g., the work of Lu et al. ${ }^{[22]}$ who have developed a pure PEDOT:PSS hydrogel with high electrical conductivity, high stretchability, and superior stability as a promising electrical interface with biological tissues for sensing and stimulation.

Although, it should be noted that among all those possible applications, we can highlight the organic light-emitting diodes (OLED) and non-emissive electrochromic devices (ECD), which require a fine-tuning of colors in terms of its tonality, saturation, intensity, and brightness ${ }^{[4]}$. Different strategies in synthesis have been described to reach new materials with the largest planarity as possible, increasing the chain length and alternating between donating and accepting electron groups, systems named D-A, for increase conjugation $^{[4]}$.
The correlation and influence of the monomer structure under the material electrochromic properties can be verified, particularly on the work of Dyer et al. ${ }^{[23]}$. Such investigation showed that for D-A based polymers, it might be possible to build multicolored electrochromic devices with high efficiency, whose color change follows the composition and photoelectrochemical properties of the material. Nowadays, it can be found a considerable number of publications concerning the D-A-like copolymers with different substituted thiophenes ${ }^{[9,24]}$, which makes it very interesting to put efforts on this research line.

From the 80's, the use of spectroelectrochemical techniques (coupling spectroscopic and electrochemical techniques) emerged in several research lines, e.g., on the conducting polymers field, where the UV-Vis spectroscopy is widely used to determine electrochromic parameters as well to investigate the electrochemical kinetic $^{[6,25-27]}$. Worldwide, we can find plenty of works reporting the synthesis of thiophene-based copolymers and their spectroelectrochemical behavior. In this way, Vogel and Holze ${ }^{[28]}$ have published a work presenting the electrosynthesis of aniline-thiophene copolymers with a new spectroelectrochemical behavior with a slight prevailing of aniline in such properties. 
In another example, Zagorska et al. ${ }^{[29]}$ have synthesized copolymers based on 3-alkylthiophenes and thiophene functionalized with an azo chromophore leading to a mix of electrochromic properties. Alakhras has also published a work presenting new copolymers obtained potentiostatically from selenophene and thiophene units, which provided changes on the electro-optical properties ${ }^{[30]}$. Another work mentions the preparation of a copolymer of 2,5-di(thiophen-2-yl)-1-p-tolyl-1H-pyrrole (DTTP) with 3,4-ethylenedioxythiophene (EDOT) ${ }^{[31]}$. Through the spectroelectrochemical characterization, the electrochromic parameters of such copolymer have shown to be better than the homopolymer, such a lower energy band gap, optical contrast of $20 \%$ and a switching time less than $1 \mathrm{~s}^{[31]}$.

Regarding the electrical behavior of copolymers, Chen et al. ${ }^{[32]}$ have synthesized a copolymer based on 3,4-ethylenedioxythiophene (EDOT) and 3-thienyl ethoxybutanesulfonate (TEBS) showing conductivity almost 6 times higher than compared with pure homopolymer (PEDOT). In the same way, Ates and Ekmen prepared an EDOT-pyrrole (Py) copolymer with a slight gain on the capacitance when compared with both homopolymers that could be a promising electrode material for high-performance electrical energy storage devices ${ }^{[33]}$. In a different approach, Kulandaivalu et al. ${ }^{[34]}$ prepared a copolymer of EDOT and aniline by electrodeposition and performed electrochemical impedance spectroscopy experiments to understand its electrical behavior and proposed a path to analyze the results, which explained that the incorporation of the EDOT in aniline makes the interfacial resistance of the copolymer to be lower than neat polyaniline.

Yijie et al. ${ }^{[35]}$ have proposed the electrosynthesis of D-A-like copolymers containing a benzothiadiazole unit as the acceptor monomer and different thiophene derivatives as the donating units. In this way, they were able to manage the fine-tuning colors of the materials in booth neutral and oxidized state by varying the electron-rich character of the incorporated thiophene moieties.

We have published a previous work about the synthesis and structural characterization of thiophene monomers: 3-thiophene phenylacetate - PhTAc-2a, 3-thiophene(4-nitrophenyl)acetate - PhTAc-2b, and 3-thiophenephenylcarboxylate - $\mathrm{PhTCb}$, as well as the synthesis and electrochemical characterization of their copolymers with EDOT. In this work, we have given sequence on the characterization of these materials by performing spectroelectrochemical experiments, in order to figure out the electrochromic properties of these donor-acceptor copolymers. Besides, we have run chronoabsorptometry experiments, which allowed us to calculate important electrochromic parameters, such as optical contrast, coloration efficiency, and switching times. Finally, we have studied the electrical profile of those materials by the EIS technique. These experiments and properties for PEDOT film are well known. Therefore, it is essential to mention that we have performed the experiments for PEDOT film just in order to compare its results with the copolymers ones.

\section{Materials and Methods}

\subsection{Materials}

The electron-acceptor monomers: 3-thiophene phenylacetate (PhTAc-2a), 3-thiophene(4-nitrophenyl)acetate (PhTAc-2b), and 3-thiophenephenylcarboxylate (PhTCb) were synthesized and characterized on previous work. More detailed information about the electropolymerization and characterization of these copolymers can be found in previous work ${ }^{[36]}$.3,4-ethylenedioxythiophene (EDOT, 97\%) and sodium perchlorate $\left(\mathrm{NaClO}_{4}, 98 \%\right)$ were purchased from Aldrich. Acetonitrile (ACS) was purchased from Synth. The indium tin oxide $($ ITO $)$ coated glasses $(8-12 \Omega ; 7.0 \times 50.0 \times 0.7 \mathrm{~mm})$ were purchased from Delta Technologies.

\subsection{Preparation of the $D-A$ copolymers}

After testing the oxidizing potential for the electron-acceptor monomers ${ }^{[36]}$, solutions of these monomers with EDOT have been prepared in acetonitrile containing $0.1 \mathrm{M}$ of $\mathrm{NaClO}_{4}$ and using a content of 4:1 (moles/moles) of EDOT:monomer. The films for the spectroelectrochemical characterization were electrodeposited onto ITO coated glass by cyclic voltammetry ( 20 cycles at a scanning rate of $50 \mathrm{mV} \mathrm{s}^{-1}$ ) through a PalmSens potentiostat. For the electrochemical impedance spectroscopy measurements, freshly films have been prepared onto a platinum working-electrode $\left(0.01 \mathrm{~cm}^{2}\right)$ also by cyclic voltammetry under the same conditions cited before.

\subsection{Spectroelectrochemical characterization}

After washed with acetonitrile, each thin film substrate was transferred to a quartz cuvette $(1.0 \mathrm{~cm})$ filled with a $0.1 \mathrm{M} \mathrm{NaClO}_{4}$ /acenotrile solution. On the cuvette, it was attached a platinum wire as counter-electrode and a silver wire as pseudo-reference. This system was put into a spectrophotometer (Varian - Cary 100 Bio) to measure the spectra for different potentials applied. Before the readings, it was applied the conditioning potential during $50 \mathrm{~s}$ through a PalmSens potentiostat. The steps of potential were $0.3 \mathrm{~V}$, contemplating the electroactivity window of each copolymer.

On the sequence, new copolymer films were prepared, also on ITO coated glass, to run the chronoabsorptometry experiments using the same spectrophotometer and a PGSTAT204 potentiostat to record the chronoamperometry curves. In this case, it was also used a quartz cuvette containing $0.1 \mathrm{M} \mathrm{NaClO}_{4} /$ acetonitrile and the same electrodes as described before. Through the potentiostat, the potential was switched starting from the lowest (neutral) to the highest (oxidized). Each potential was applied during $10 \mathrm{~s}$ and, simultaneously, the transmittance variation and chronoamperometry curves have been recorded.

The transmittance variation curves allow determining the response times to the bleaching/coloring processes by measuring the time taken when the transmittance changing reaches $95 \%$. In addition, it is possible to calculate other electrochromic parameters from the transmittance and amperograms curves, such as the optical contrast $(\Delta T)$ - the difference between colored and bleached states transmittance, and the coloration efficiency $(\eta)$ - calculated from the equation $^{[37]}$ : 


$$
\eta=\frac{\Delta \mathrm{OD}}{\Delta \mathrm{Q}}
$$

where $\triangle O D$ is the optical density variation in a fixed wavelength; and $\Delta Q$ is the sum of injected/ejected charges per surface unit. We can use the following equation to determine the $\triangle O D$ value:

$$
\Delta \mathrm{OD}=\log \left(\mathrm{T}_{\text {red }} / \mathrm{T}_{\text {ox }}\right)
$$

where $T_{\text {red }}$ is the bleached state transmittance; and $T_{\text {ox }}$ is the colored state transmittance.

\subsection{Electrochemical Impedance Spectroscopy (EIS) characterization}

The EIS curves (Nyquist diagrams), were measured with a PGSTAT potentiostat in a three-electrode system $\left(\mathrm{WE}=\mathrm{CE}=\mathrm{Pt}\right.$, and $\left.\mathrm{RE}=\mathrm{Ag} / \mathrm{Ag}^{+}\right)$using a $0.1 \mathrm{M} \mathrm{NaClO}_{4}$ /acetonitrile as electrolytic solution. To scheduling the experiments, two potentials $\left(E_{\mathrm{dc}}\right)$ were used: $-0.5 \mathrm{~V}$ (reduced polymer) and $1.5 \mathrm{~V}$ (oxidized polymer), excitation amplitude of $10 \mathrm{mV}$ and frequency range from $100 \mathrm{kHz}$ to $10 \mathrm{mHz}$. The thickness of PEDOT and its copolymers studied by EIS were estimated from the film polymerization charges, assuming 2.25 electrons per monomer and a film density of $1 \mathrm{~g} \mathrm{~cm}^{-3[38]}$.

The representation of the electric behavior of our cell can be assimilated to a Randle circuit, which circuit is usual in electrochemistry ${ }^{[39]}$. In this equivalent circuit based on the simple process, we have the electrolyte resistance, $R_{\mathrm{s}}$, the double-layer capacitance, $C_{\mathrm{dl}}$, and the faradaic impedance $Z_{\mathrm{f}}$. This last one translates the faradic processes that depend on the frequency and consequently cannot be represented by simple linear circuit elements. A typical representation of $Z_{\mathrm{f}}$ is a charge transfer resistance in series with a pseudo-capacitance or the same resistor in series with a Warburg impedance which is a type of resistance to mass transfer. This equivalent circuit illustrates the usual behavior of the conductive polymers and corresponds to either the simple diffusion-kinetic model or the distributed transmission line model or the more complex model that describes the mixed electron and ionic conduction taking into account the percolation of charge by electromigration ${ }^{[40]}$.

The determination of the parameters of the circuit was not performed from the simulation of the equivalent circuit. We calculate these values directly from the impedance diagrams using boundary conditions. $R_{\mathrm{s}}$ is determined through the diagram's intersections with the $Z^{\prime}$ axis at high frequencies, $R_{\mathrm{ct}}$ is determined to estimate the semicircle diameter and $C_{\mathrm{dl}}$ is calculated from the following relation:

$$
\mathrm{C}_{\mathrm{dl}}=\frac{1}{2 \pi \mathrm{R}_{\mathrm{ct}} \mathrm{f}}
$$

where $f$ is the frequency that corresponds to the maximum of the half-circle.

The low-frequency capacitance, $C_{1 \mathrm{f}}$, is calculated from the following relation:

$$
\mathrm{C}_{\mathrm{lf}}=\frac{1}{2 \pi \mathrm{f}\left|\mathrm{Z}^{\prime \prime}\right|}
$$

where $Z$ " is the imaginary part of the EIS spectra.

\section{Results and Discussions}

\subsection{Spectroelectrochemistry}

In order to know the electroactivity window suitable for each copolymer, the films have been characterized by cyclic voltammetry $\left(25 \mathrm{mV} \mathrm{s}^{-1}\right)$ in a monomer-free solution containing $0.1 \mathrm{M}$ of $\mathrm{NaClO}_{4} /$ acetonitrile. The voltammograms and the respective chemical structure of these copolymers are presented on Figure 1. Figure 2 shows the spectroelectrochemical results, whose inset graph presents the absorbance variation curves in function of the potential applied, for each corresponding maximum absorbance wavelength.

After the analysis of the spectroelectrochemical curves, it can be observed that PEDOT and copolymers films presented an absorption band in the high-energy side of the spectrum when in their reduced state. As we apply the shifts of potential, the energetic states of the polymer change that is corroborated by the quenching of the transition between the valence band (VB) and conducting band (CB), also to the appearance of a band near to the infrared region. This band appearance is linked to the generation of new energy levels inside the band gap during the doping process, which leads to polaron and bipolaron states generation ${ }^{[4]}$.

Also, all the films presented color changing in function of the conditioning potential, going from a colored neutral state to a colored oxidized state. Indeed, PEDOT-co- PhTAc-2a film presented a brownish neutral state and a grayish oxidized state, PEDOT-co-PPhTAc-2b changed from dark-purple to light-blue, and PEDOT-co-PPhTCb changed from purple to grayish-green.

In general, all the spectroelectrochemical curves from the copolymers seemed to be similar to PEDOT curves, and this may be explained by the higher amount of EDOT monomer in the copolymer backbone so that it could be expected a more significant influence of EDOT over the spectroelectrochemistry.

The maximum absorption value to the films at reduced state, as well as the onset energy and the molecular orbital energies for each polymer, are presented in Table 1 below. The onset energy was extracted from the Tauc curves (Figure S1 at the Supplementary Material section) and the HOMO energy was calculated through the onset of the anodic peak potential (extracted from the voltammogram).

The band gap and the molecular orbital levels (HOMO and LUMO) for PEDOT film are corroborated with the literature ${ }^{[42]}$. This table shows that the copolymers presented a shift towards the high-energy side of the spectrum (hypsochromic shift) in comparison to PEDOT, which may be explained by the presence of substituted groups on the polymeric structure, rising the possible electronic transitions. This shift was lower for PEDOT-co-PPhTCb since there is more electron delocalization due to the resonance effect of the group $-\mathrm{COOPh}$, directly attached to the thiophene ring ${ }^{[36]}$. On the other hand, PEDOT-co-PPhTAc-2b presented the opposite effect: the band shifting to the low-energy spectrum region (bathochromic shift), which corroborates the influence of the electron-withdrawing effect of the nitro group ${ }^{[36]}$. When we observe the band gap values $\left(E_{\mathrm{g}}\right)$, it is evident a bathochromic shift found to copolymer films, referring to a decrease on the transition energy value, which may be linked, 

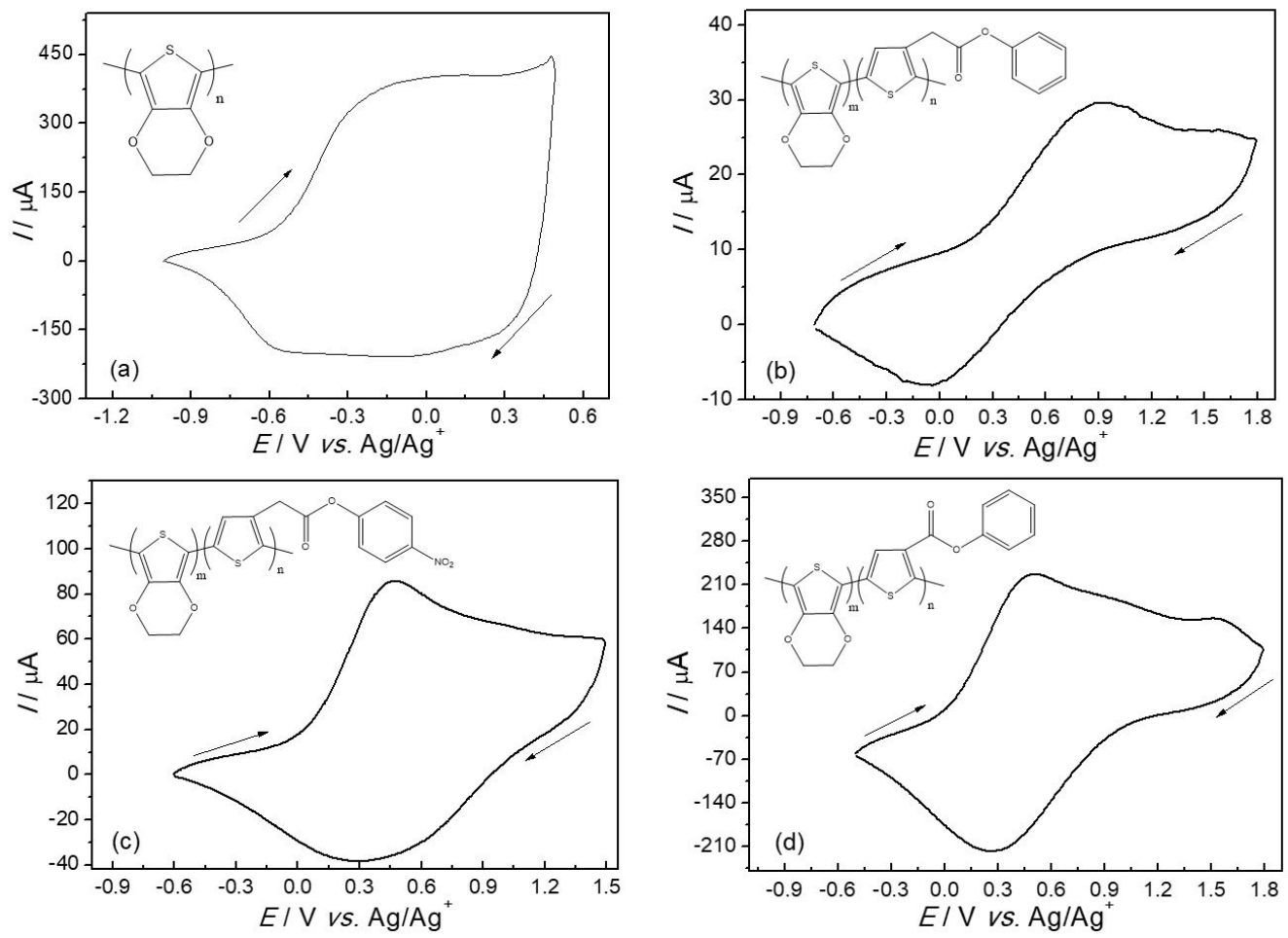

Figure 1. Cyclic voltammograms and chemical structure for PEDOT (a), PEDOT-co-PPhTAc-2a (b), PEDOT-co-PPhTAc-2b (c) and PEDOT-co-PPhTCb (d); $E / \mathrm{V}=$ potential/volts, $\mathrm{Ag}=$ silver, $\mu \mathrm{A}=$ microampere.
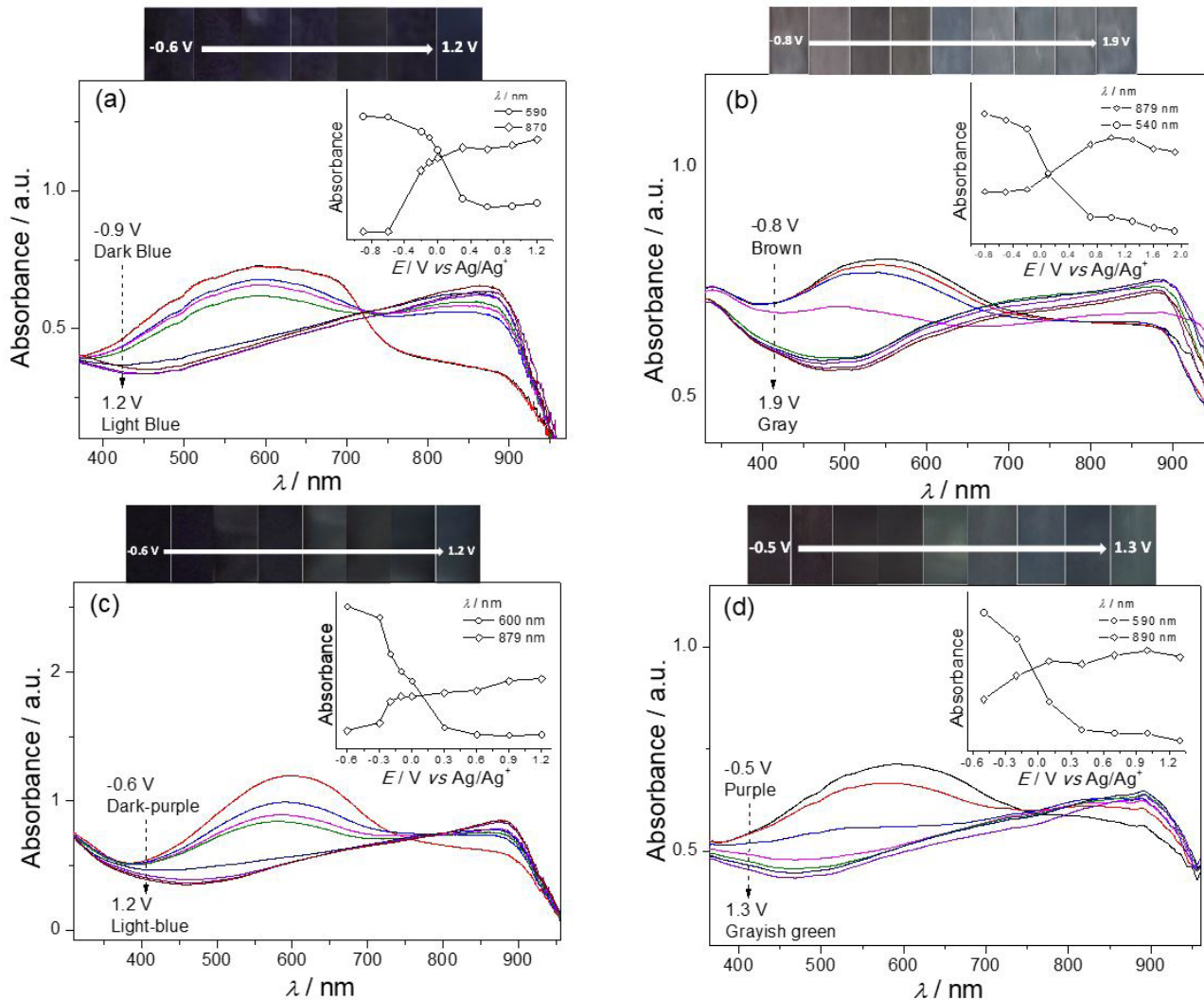

Figure 2. Spectroelectrochemical curves and digital photographs to the films of PEDOT (a), PEDOT-co-PPhTAc-2a (b), PEDOT-co-PPhTAc-2b (c) and PEDOT-co-PPhTCb (d); $E / \mathrm{V}=$ potential/volts, $\mathrm{Ag}=$ silver, $\lambda / \mathrm{nm}=$ wavelength/nanometers. 
Table 1. Data of maximum of absorption $\left(\lambda_{\max }\right)$, transition onset energy $\left(E_{\mathrm{g}}\right)$, highest occupied molecular orbital $(\mathrm{HOMO})$ and lowest unoccupied molecular orbital (LUMO) energy levels for PEDOT and the D-A copolymers; determined under reduction potential $(E)$.

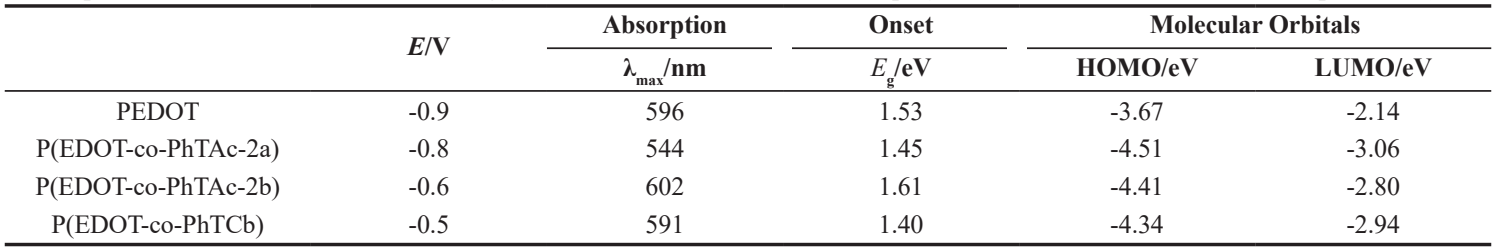

Table 2. Data of optical contrast $(\Delta T)$, coloration efficiency $(\eta)$, oxidation switching time $\left(\tau_{\mathrm{ox}}\right)$, and reduction switching time $\left(\tau_{\text {red }}\right)$ for PEDOT and copolymer films.

\begin{tabular}{|c|c|c|c|c|c|}
\hline & Thickness/nm & $\Delta T$ & $\eta / \mathrm{cm}^{2} \mathrm{C}^{-1}$ & $\tau_{\mathrm{ox}} / \mathrm{s}$ & $\tau_{\text {red }} / \mathrm{s}$ \\
\hline PEDOT & 24.9 & 27.63 & 40.55 & 1.10 & 1.97 \\
\hline P(EDOT-co-PhTAc-2a) & 10.5 & 10.18 & 43.79 & 1.38 & 1.54 \\
\hline P(EDOT-co-PhTAc-2b) & 15.5 & 19.01 & 304.7 & 1.81 & 2.58 \\
\hline P(EDOT-co-PhTCb) & 65.5 & 12.70 & 37.61 & 1.15 & 1.21 \\
\hline
\end{tabular}
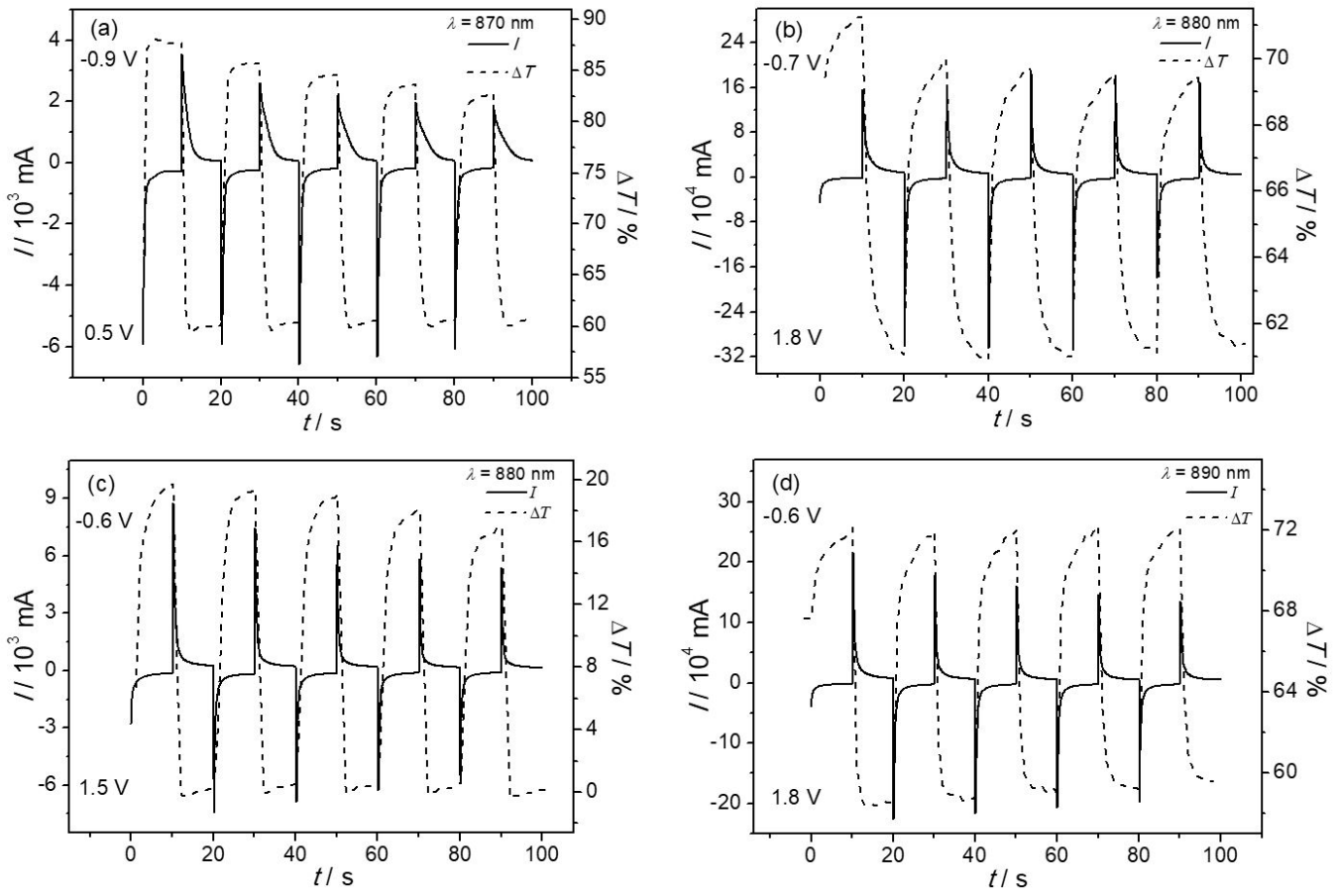

Figure 3. Transmittance spectra (dashed line) and chronoamperograms (solid line) to the films of PEDOT (a), PEDOT-co-PPhTAc-2a (b), PEDOT-co-PPhTAc-2b (c) and PEDOT-co-PPhTCb (d); $t / \mathrm{s}=$ time/seconds.

again, to the D-A groups effect, meaning a larger electronic density conjugation, and in turn, decreasing the transition energy value ${ }^{[36]}$. On the contrary, it was observed a slight increase in the band gap energy for PEDOT-co-PPhTAc-2b, which may probably be linked to the electron-withdrawing effect of the nitro group.

The chronoabsorptometry curves (Figure 3 ) show the transmittance spectra on the UV-Vis region versus time and the chronoamperograms. Then, it was possible to measure the switching times for coloration and bleaching processes beyond calculating the electrochromic parameters using Equations 1 and 2. These results are presented in Table 2.

By taking a look into Table 2, PEDOT-co-PPhTAc-2b film has presented coloration efficiency almost 7.5 times higher than neat PEDOT. This behavior may be related to the nitro group presence, acting as a strong electron-withdrawing group, fortifying the electron-acceptor effect of the PhTAc-2b block ${ }^{[36]}$. All copolymer films have presented moderately fast switching times located on the scale of a few seconds, as observed in other works ${ }^{[3-46]}$. Besides, we have noticed that the copolymers, based on electron-acceptor monomers that possess a methylene group (PhTAc-2a and PhTAc-2b), presented the highest switching times. On the contrary, PEDOT-co-PPhTCb film, which does not have this methylene group, has presented faster switching times, which might be associated with a direct conjugation path among the D-A blocks, increasing the conjugation length and, therefore, decreasing the response times.

It is well-known from the literature that the thickness of the film directly interferes in the electrochromic properties, 
where the higher thickness is supposed to lead to greater performances ${ }^{[4]}$. The thickness found for the copolymers reported on Table 2, even neat PEDOT, was much lower when compared with other D-A copolymers and, therefore, the values of optical contrast and coloration efficiency were quite lower ${ }^{[47-49]}$. Nevertheless, with thickness, almost twice lower than PEDOT, P(EDOT-co-PhTAc-2a) and $\mathrm{P}($ EDOT-co-PhTAc-2b) films have presented electrochromic properties similar or even higher than neat PEDOT, which is an improvement after all.

Another fact that may influence over the electrochromic properties of the polymer is the methodology used during the electropolymerization process. Gu et al. ${ }^{[50]}$ have employed chronoamperometry method to prepare an isoindigo-based donor-acceptor polymer with EDOT and exhibiting an outstanding electrochromic performance with coloration efficiency around $360 \mathrm{~cm}^{2} \mathrm{C}^{-1}$, fast switching time of $0.5 \mathrm{~s}$, and high optical contrast of almost $60 \%$. Indeed, the chronoamperometry is a faster technique to grow thicker polymeric films when compared to the cyclic voltammetry. Once the polymers of this work have been electropolymerized through cyclic voltammetry, this explains the lower thickness and, consequently, the apparent poor values of electrochromic parameters.

\subsection{Electrochemical Impedance Spectroscopy (EIS)}

The impedance experiments took place by applying two potentials: $E_{\mathrm{dc}}=-0.5 \mathrm{~V}$ - reduced polymer and $E_{\mathrm{dc}}=1.5 \mathrm{~V}$-oxidized polymer. Figure 4a below shows, on the shape of the Nyquist diagram, the impedance results, at low frequencies, obtained for PEDOT and its several copolymers at the oxidized state $\left(E_{\mathrm{dc}}=1.5 \mathrm{~V}\right)$. On the other hand, Figure $4 \mathrm{~b}$ shows the impedance results at high frequencies.

As it can be observed, at higher frequencies, the PEDOT behavior is in agreement with the literature results ${ }^{[38]}$, pointing the presence of an almost vertical line, Figure $3 \mathrm{~b}$, typical of a capacitive behavior, and indicating a fast electrical charge transfer at the interface metal $\mid$ PEDOT $\mid$ electrolyte. However, to the copolymers, this electronic transference appears to be slower and it is translated by line with a slope $<90^{\circ}$. The profile observed at low frequencies, Figure $3 a$, it was also observed by Bobacka et al. ${ }^{[38]}$, and it is assigned to a reaction that happens in parallel to the electrode doping that might be related to the presence of oxygen traces in the electrolyte solution. This behavior fits with the model proposed by Vorotyntsev et al. ${ }^{[51]}$, which counts a charge transfer involving the ionic and electronic shape between the polymer and the solution. The intersection at high frequencies of the Nyquist diagrams with $Z^{\prime}$ axis is mainly related to the electrolyte resistance, amount near to $150 \Omega$ for PEDOT and $200 \Omega$ for copolymers. This variation might be since this resistance would also exist a resistive contribution due to the polymer | platinum interface. We have neglected effects due to the ohmic resistance (electronic) of the oxidized films since we will see in the following part that in the reduced state, the behavior of this high-frequency resistance is the same.

The Nyquist diagrams recorded at reduced state $\left(E_{\mathrm{dc}}=-0.5 \mathrm{~V}\right)$ are presented in Figure 5. At lower frequencies (Figure 5a), the behaviors are similar and show a vertical
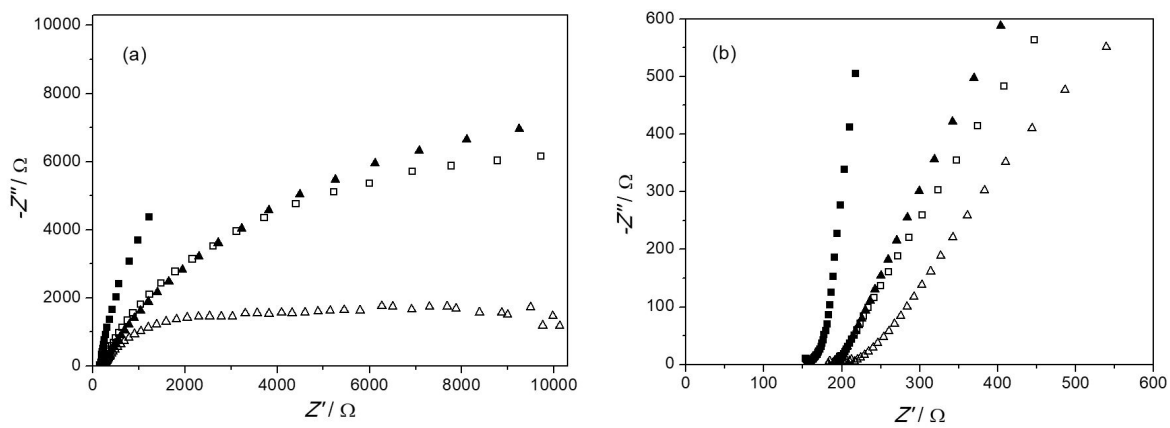

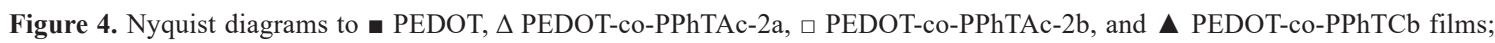
$E_{\mathrm{dc}}=1.5 \mathrm{~V}$; (a) low frequencies; (b) high frequencies; $Z=$ impedance.
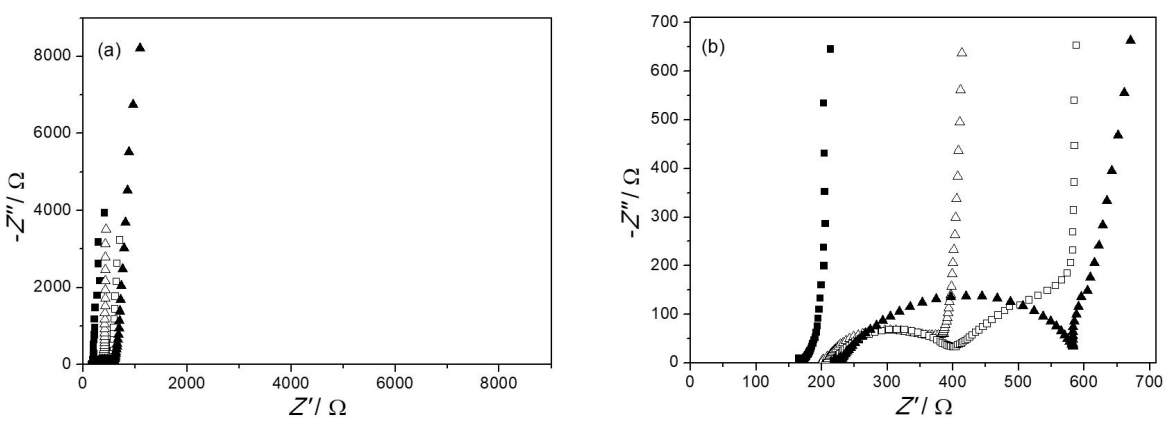

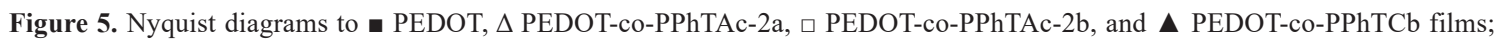
$E_{\mathrm{dc}}=-0.5 \mathrm{~V}$; (a) low frequencies; (b) high frequencies; $Z=$ impedance. 
Table 3. Data of resistance $\left(R_{\mathrm{s}}\right)$, charge transfer resistance $\left(R_{\mathrm{ct}}\right)$, double-layer capacitance $\left(C_{\mathrm{dl}}\right)$, and low-frequency capacitance $\left(C_{\mathrm{lf}}\right)$ to PEDOT and copolymers films.

\begin{tabular}{ccccc}
\hline & $\boldsymbol{R}_{\mathbf{s}} /\left(\boldsymbol{\Omega} \mathbf{~ c m}^{-2}\right)$ & $\boldsymbol{R}_{\mathbf{c t}} /\left(\mathbf{\Omega} \mathbf{~ c m}^{-2}\right)$ & $\boldsymbol{C}_{\mathrm{dl}} /\left(\boldsymbol{\mu} \mathbf{F} \mathbf{~ m}^{-2}\right)$ & $\boldsymbol{C}_{\mathrm{it}} /\left(\mathbf{F} \mathbf{g}^{-1} \mathbf{c m}^{-2}\right)$ \\
\hline PEDOT & 16,900 & - & - & 488,400 \\
PEDOT-co-PPhTAc-2a & 20,000 & 20,000 & 190 & $1,355,800$ \\
PEDOT-co-PPhTAc-2b & 21,900 & 19,600 & 86 & 920,300 \\
PEDOT-co-PPhTCb & 22,200 & 36,000 & 110 & 87,300 \\
\hline
\end{tabular}

line with a slope near to $90^{\circ}$ (capacitive profile). Figure $5 \mathrm{~b}$ illustrates the behavior at higher frequencies.

The four copolymers have shown similar diagrams, which allows seeing at higher frequencies, in the diagrams intersection with the $Z^{\prime}$ axis, a resistance near to $200 \Omega$ and, as in the oxidized state, which can be assigned to the electrolyte resistance associated in series with the polymer | platinum interface resistance. At intermediate frequencies, it is observed a characteristic semicircle of the double-layer resistance in parallel with the charge transfer resistance. Furthermore, at lower frequencies, the behavior seems to be purely capacitive, with an almost vertical line crossing over the $Z^{\prime}$ axis. Peculiarly, PEDOT-co-PPhTAc-2b shows, at intermediate frequencies, a Warburg behavior, translated by a line with a slope near to $45^{\circ}$ - related to the observation of the diffusive process during the polymer redox reactions. At the PEDOT diagram, it is only observed the capacitive process and it was no possible to see the semicircle presented in the copolymers diagrams. In Table 3, the impedance values are presented for each process seen in Figure $4 \mathrm{a}$ and Figure $4 b$ diagrams.

Differently from PEDOT, the copolymers have presented a $R_{\mathrm{ct}}$ value quite high, indicating a greater difficulty for charge transfer. The electron-acceptor effect of the substituent influences at position 3 on the thiophene ring over the data of resistance obtained is also notable. In the same way, as presented out in the switching times analysis, the $\mathrm{PhTCb}$ copolymer has shown a more significant variation of $R_{\mathrm{ct}}$ value, perhaps also due to the direct conjugation between the thiophene ring and the carboxylic substituent, which may worsen even more the charge transfer.

On the other hand, the $C_{\mathrm{dl}}$ values are compatible with the double-layer capacitance values usually expected for platinum in contact with the electrolyte ${ }^{[52,53]}$, confirming the porosity of the films.

It is noteworthy that the $C_{\text {If }}$ values were quite high, indicating such materials as promising candidates for supercapacitors devices building, and this might be due to the efficient electron conjugation between the electron-donor monomer (EDOT) and electron-acceptor monomers (PhTAc-2a, PhTAc-2b, and PhTCb) from the D-A system, proposed in this work.

If we make a comparison between spectroelectrochemical and impedance results, it is possible to observe that when the polymer remains reduced or neutral, it presents a higher resistance. Instead, when the polymer is oxidized, it is noticed the arising of new energetic states within the band gap, and the resistance became lowest.

\section{Conclusions}

In this work, the spectroelectrochemical experiments have shown that D-A-like copolymers prepared by electropolymerization of EDOT and electron-acceptor thiophene derivatives have presented electrochromism. Such color changing was visually noticed, beyond observing the arising of new bands at the absorption spectrum as the potential changes.

Additionally, through the experiments of chronoabsorptometry, it was possible to determine some electrochromic parameters indispensable to study the device building viability, like the optical contrast and the coloration efficiency, beyond the switching times to electrochemical stimulation, in which those D-A-like copolymers have demonstrated a potential application on electrochromic devices building.

The impedance results show that in the oxidized state, there is a fast electrical charge transfer at the interface metal | polymer | electrolyte and in the reduced state, the charge transfer is much slower and there is a purely capacitive behavior at low frequencies. Finally, the $C_{\mathrm{dl}}$ values have confirmed the film porosity and capacitive profile at low frequencies indicating that those materials also have potential applicability to supercapacitors building.

\section{Acknowledgements}

This work was partially supported by the Brazilian Institute of Science and Technology in Carbon Nanomaterials (INCT) and the Brazilian agencies CAPES, CNPq [457586/2014-1 and 4076186/2013-1], FAPEMIG [CEX - PPM-281-17, CEX - PPM-00916-15, and TEC - APQ-02715-14], and Rede Mineira de Química (RQ-MG). Marcus Henrique de Araujo gratefully thanks the scholarship received from CAPES. The authors also thank $\mathrm{LaMPaC} / \mathrm{UFMG}$ for providing infrastructure to run the EIS experiments.

\section{References}

1. Mishra, A., Ma, C. Q., \& Bauerle, P. (2009). Functional oligothiophenes: molecular design for multidimensional nanoarchitectures and their applications. Chemical Reviews, 109(3), 1141-1276. http://dx.doi.org/10.1021/cr8004229. PMid:19209939.

2. Perepichka, I. F., \& Perepichka, D. F. (2009). Handbook of thiophene-based materials: applications in organic electronics and photonics. Chichester: Wiley. http://dx.doi. org/10.1002/9780470745533.

3. Vasilyeva, S. V., Beaujuge, P. M., Wang, S. J., Babiarz, J. E., Ballarotto, V. W., \& Reynolds, J. R. (2011). Material strategies for black-to-transmissive window-type polymer electrochromic 
devices. Applied Materials \& Interfaces, 3(4), 1022-1032. http://dx.doi.org/10.1021/am101148s.

4. Beaujuge, P. M., \& Reynolds, J. R. (2010). Color control in pi-conjugated organic polymers for use in electrochromic devices. Chemical Reviews, 110(1), 268-320. http://dx.doi. org/10.1021/cr900129a. PMid:20070115.

5. Zhao-yang, Z., Yi-jie, T., Xiao-qian, X., Yong-jiang, Z., Hai-feng, C., \& Wen-wei, Z. (2012). Electrosynthesises and characterizations of copolymers based on thiophene and 3,4-ethylenedioxythiophene in boron trifluoride diethyl etherate. Synthetic Metals, 162(23), 2176-2181. http://dx.doi. org/10.1016/j.synthmet.2012.10.011.

6. Ming, S., Zhang, S., Liu, H., Zhao, Y., Mo, D., \& Xu, J. (2015). Methacrylate modified polythiophene: electrochemistry and electrochromics. International Journal of Electrochemical Science, 10(8), 6598-6609. Retrieved in 2019, May 12, from http://www.electrochemsci.org/papers/vol10/100806598.pdf

7. Lee, J. U., Jung, J. W., Emrick, T., Russell, T. P., \& Jo, W. H. (2010). Synthesis of C(60)-end capped P3HT and its application for high performance of P3HT/PCBM bulk heterojunction solar cells. Journal of Materials Chemistry, 20(16), 3287-3294. http://dx.doi.org/10.1039/b923752f.

8. Hu, X. L., Zuo, L. J., Nan, Y. X., Helgesen, M., Hagemann, O., Bundgaard, E., Shi, M. M., Krebs, F. C., \& Chen, H. Z. (2012). Fine tuning the HOMO energy levels of polythene 3,4-b thiophene derivatives by incorporation of thiophene-3,4dicarboxylate moiety for photovoltaic applications. Synthetic Metals, 162(23), 2005-2009. http://dx.doi.org/10.1016/j. synthmet.2012.10.001.

9. Kim, H., Lee, H., Jeong, Y., Park, J. U., Seo, D., Heo, H., Lee, D., Ahn, Y., \& Lee, Y. (2016). Donor acceptor polymers with a regioregularly incorporated thieno 3,4-b thiophene segment as a pi-bridge for organic photovoltaic devices. Synthetic Metals, 211, 75-83. http://dx.doi.org/10.1016/j.synthmet.2015.11.016.

10. Kim, J. H., \& Park, J. G. (2015). Effect of donor weight in a P3HT:PCBM blended layer on the characteristics of a polymer photovoltaic cell. Journal of the Korean Physical Society, 66(11), 1720-1725. http://dx.doi.org/10.3938/jkps.66.1720.

11. Bora, C., Sarkar, C., Mohan, K. J., \& Dolui, S. (2015). Polythiophene/graphene composite as a highly efficient platinum-free counter electrode in dye-sensitized solar cells. Electrochimica Acta, 157, 225-231. http://dx.doi.org/10.1016/j. electacta.2014.12.164.

12. Zhang, J., Li, X. X., Guo, W., Hreid, T., Hou, J. F., Su, H. Q., \& Yuan, Z. B. (2011). Electropolymerization of a poly(3,4ethylenedioxythiophene) and functionalized, multi-walled, carbon nanotubes counter electrode for dye-sensitized solar cells and characterization of its performance. Electrochimica Acta, 56(9), 3147-3152. http://dx.doi.org/10.1016/j.electacta.2011.01.063.

13. Vashchenko, A. A., Vitukhnovsky, A. G., Taidakov, I. V., Tananaev, P. N., Vasnev, V. A., Rodlovskaya, E. N., \& Bychkovsky, D. N. (2014). Organic light-emitting devices with multi-shell quantum dots connected with polythiophene derivatives. Semiconductors, 48(3), 377-380. http://dx.doi.org/10.1134/ S1063782614030269.

14. Qu, B., Feng, L. M., Yang, H. S., Gao, Z., Gao, C., Chen, Z. J., Xiao, L. X., \& Gong, Q. H. (2012). Color-stable deep redemitting OLEDs based on a soluble terpolyrner containing fluorene, thiophene and benzothiadiazole units. Synthetic Metals, 162(17-18), 1587-1593. http://dx.doi.org/10.1016/j. synthmet.2012.06.021.

15. Gupta, N., Grover, R., Mehta, D. S., \& Saxena, K. (2016). A simple technique for the fabrication of zinc oxide-PEDOT:PSS nanocomposite thin film for OLED application. Synthetic Metals, 221,261-267. http://dx.doi.org/10.1016/j.synthmet.2016.09.014.
16. Zhu, L. M., Shi, W., Zhao, R. R., Cao, Y. L., Ai, X. P., Lei, A. W., \& Yang, H. X. (2013). n-Dopable polythiophenes as high capacity anode materials for all-organic $\mathrm{Li}$-ion batteries. Journal of Electroanalytical Chemistry, 688, 118-122. http:// dx.doi.org/10.1016/j.jelechem.2012.06.019.

17. Zhang, H. Q., Hu, L. W., Tu, J. G., \& Jiao, S. Q. (2014). Electrochemically assembling of polythiophene film in ionic liquids (ILs) microemulsions and its application in an electrochemical capacitor. Electrochimica Acta, 120, 122-127. http://dx.doi.org/10.1016/j.electacta.2013.12.091.

18. Zhen, S., Ma, X., Lu, B., Ming, S., Lin, K., Zhao, L., Xu, J., $\&$ Zhou, W. (2014). Supercapacitor electrodes based on furanEDOT copolymers via electropolymerization. International Journal of Electrochemical Science, 9(12), 7518-7527. Retrieved in 2019, May 12, from http://www.electrochemsci.org/papers/ vo19/91207518.pdf

19. Ates, M., \& Arican, F. (2015). Electrocoated films of poly(Nmethylpyrrole-co-2,2 '-Bithitiophene-co-3-(Octylthiophene)), characterizations, and capacitor study. International Journal of Polymeric Materials and Polymeric Biomaterials, 64(3), 125-133. http://dx.doi.org/10.1080/00914037.2014.909423.

20. Hu, F. Q., Xue, Y., Xu, J. K., \& Lu, B. Y. (2019). PEDOT-based conducting polymer actuators. Frontiers in Robotics and AI, 6, 17. http://dx.doi.org/10.3389/frobt.2019.00114.

21. Yuk, H., Lu, B. Y., \& Zhao, X. H. (2019). Hydrogel bioelectronics. Chemical Society Reviews, 48(6), 1642-1667. http://dx.doi. org/10.1039/C8CS00595H. PMid:30474663.

22. Lu, B. Y., Yuk, H., Lin, S. T., Jian, N. N., Qu, K., Xu, J. K., \& Zhao, X. H. (2019). Pure PEDOT:PSS hydrogels. Nature Communications, 10(1), 1043. http://dx.doi.org/10.1038/ s41467-019-09003-5. PMid:30837483.

23. Dyer, A. L., Craig, M. R., Babiarz, J. E., Kiyak, K., \& Reynolds, J. R. (2010). Orange and red to transmissive electrochromic polymers based on electron-rich dioxythiophenes. Macromolecules, 43(10), 4460-4467. http://dx.doi.org/10.1021/ma100366y.

24. Zhang, Z. Q., Liu, W. Q., Yan, J. L., Shi, M. M., \& Chen, H. Z. (2016). A bipolar diketopyrrolopyrrole molecule end capped with thiophene-2,3-dicarboxylate used as both electron donor and acceptor for organic solar cells. Synthetic Metals, 222, 211-218. http://dx.doi.org/10.1016/j.synthmet.2016.10.022.

25. Chotsuwan, C., Asawapirom, U., Shimoi, Y., Akiyama, H., Ngamaroonchote, A., Jiemsakul, T., \& Jiramitmongkon, K. (2017). Investigation of the electrochromic properties of triblock polyaniline-polythiophene-polyaniline under visible light. Synthetic Metals, 226, 80-88. http://dx.doi.org/10.1016/j. synthmet.2017.02.001.

26. Capan, A., \& Ozturk, T. (2014). Electrochromic properties of 3-arylthieno 3,2-b thiophenes. Synthetic Metals, 188, 100-103. http://dx.doi.org/10.1016/j.synthmet.2013.11.018.

27. Gora, M., Pluczyk, S., Zassowski, P., Krzywiec, W., Zagorska, M., Mieczkowski, J., Lapkowski, M., \& Pron, A. (2016). EPR and UV-vis spectroelectrochemical studies of diketopyrrolopyrroles disubstituted with alkylated thiophenes. Synthetic Metals, 216, 75-82. http://dx.doi.org/10.1016/j.synthmet.2015.09.012.

28. Vogel, S., \& Holze, R. (2005). Spectroelectrochernistry of intrinsically conducting aniline-thiophene copolymers. Electrochimica Acta, 50(7-8), 1587-1595. http://dx.doi. org/10.1016/j.electacta.2004.10.017.

29. Zagorska, M., Kulszewicz-Bajer, I., Pron, A., Sukiennik, J., Raimond, P., Kajzar, F., Attias, A. J., \& Lapkowski, M. (1998). Preparation and spectroscopic and spectroelectrochemical characterization of copolymers of 3-alkylthiophenes and thiophene functionalized with an azo chromophore. Macromolecules, 31(26), 9146-9153. http://dx.doi.org/10.1021/ma9806561.

30. Alakhras, F. (2016). Spectroelectrochemistry of intrinsically conducting selenophene-3-chlorothiophene copolymers. 
Journal of the Brazilian Chemical Society, 27(5), 941-949. http://dx.doi.org/10.5935/0103-5053.20150349.

31. Yigitsoy, B., Varis, S., Tanyeli, C., Akhmedov, I. M., \& Toppare, L. (2007). Electrochromic properties of a novel low band gap conductive copolymer. Electrochimica Acta, 52(23), 6561-6568. http://dx.doi.org/10.1016/j.electacta.2007.04.083.

32. Chen, J. H., Dai, C.-A., \& Chiu, W.-Y. (2008). Synthesis of highly conductive EDOT copolymer films via oxidative chemical in situ polymerization. Journal of Polymer Science. Part A, Polymer Chemistry, 46(5), 1662-1673. http://dx.doi. org/10.1002/pola.22508.

33. Ates, M., \& Ekmen, I. (2018). Capacitance behaviors of EDOT and pyrrole copolymer, and equivalent circuit model. Materials Research Innovations, 22(1), 22-36. http://dx.doi. org/10.1080/14328917.2016.1265258.

34. Kulandaivalu, S., Zainal, Z., \& Sulaiman, Y. (2015). A new approach for electrodeposition of poly (3, 4-ethylenedioxythiophene)/ polyaniline (PEDOT/PANI) copolymer. International Journal of Electrochemical Science, 10(11), 8926-8940. Retrieved in 2019, May 12, from http://http://www.electrochemsci.org/ papers/vol10/101108926.pdf

35. Yijie, T., Kai, Z., Zhaoyang, Z., Haifeng, C., Chunlin, J., \& Yulei, Z. (2016). Synthesis, characterizations, and electrochromic properties of donor-acceptor type polymers containing 2,1 , 3-benzothiadiazole and different thiophene donors. Journal of Polymer Science. Part A, Polymer Chemistry, 54(14), 22392246. http://dx.doi.org/10.1002/pola.28097.

36. Araujo, M. H., Matencio, T., Donnici, C. L., \& Calado, H. D. R. (2016). Synthesis and electrochemical investigation of betasubstituted thiophene-based donor-acceptor copolymers with 3,4-ethylenedioxythiophene (EDOT). Journal of Solid State Electrochemistry, 20(9), 2541-2550. http://dx.doi.org/10.1007/ s10008-016-3297-1.

37. Bechinger, C., Burdis, M. S., \& Zhang, J. G. (1997). Comparison between electrochromic and photochromic coloration efficiency of tungsten oxide thin films. Solid State Communications, 101(10), 753-756. http://dx.doi.org/10.1016/S0038-1098(96)00703-X.

38. Bobacka, J., Lewenstam, A., \& Ivaska, A. (2000). Electrochemical impedance spectroscopy of oxidized poly $(3,4-$ ethylenedioxythiophene) film electrodes in aqueous solutions. Journal of Electroanalytical Chemistry, 489(1-2), 17-27. http:// dx.doi.org/10.1016/S0022-0728(00)00206-0.

39. Bard, A. J., \& Faulkner, L. R. (2001). Electrochemical methods: fundamentals and applications. New York: Wiley.

40. Bonazzola, C., \& Calvo, E. J. (1998). An electrochemical impedance and spectroelectrochemical study of the polypyrroleflavin composite electrode. Journal of Electroanalytical Chemistry, 449(1-2), 111-119. http://dx.doi.org/10.1016/ S0022-0728(98)00047-3.

41. Bredas, J. L., \& Street, G. B. (1985). Polarons, bipolarons, and solitons in conducting polymers. Accounts of Chemical Research, 18(10), 309-315. http://dx.doi.org/10.1021/ar00118a005.

42. Spencer, H. J., Skabara, P. J., Giles, M., McCulloch, I., Coles, S. J., \& Hursthouse, M. B. (2005). The first direct experimental comparison between the hugely contrasting properties of PEDOT and the all-sulfur analogue PEDOT by analogy with well-defined EDTT-EDOT copolymers. Journal of Materials Chemistry, 15(45), 4783-4792. http://dx.doi.org/10.1039/b511075k.

43. Zhao, H., Tang, D. D., Zhao, J. S., Wang, M., \& Dou, J. M. (2014). Two novel ambipolar donor-acceptor type electrochromic polymers with the realization of RGB (red-green-blue) display in one polymer. RSC Advances, 4(106), 61537-61547. http:// dx.doi.org/10.1039/C4RA11628C.

44. Data, P., Zassowski, P., Lapkowski, M., Domagala, W., Krompiec, S., Flak, T., Penkala, M., Swist, A., Soloducho, J., \& Danikiewicz, W. (2014). Electrochemical and spectroelectrochemical comparison of alternated monomers and their copolymers based on carbazole and thiophene derivatives. Electrochimica Acta, 122, 118-129. http://dx.doi. org/10.1016/j.electacta.2013.11.167.

45. Yigit, D., Udum, Y. A., Gullu, M., \& Toppare, L. (2014). Electrochemical and spectroelectrochemical studies of poly(2,5-di-2,3-dihydrothieno 3,4-b 1,4 dioxin-5-ylthienyl) derivatives bearing azobenzene, coumarine and fluorescein dyes: effect of chromophore groups on electrochromic properties. Electrochimica Acta, 147, 669-677. http://dx.doi.org/10.1016/j. electacta.2014.09.053

46. Wang, Z., Xu, J. K., Lu, B. Y., Zhang, S. M., Qin, L. Q., Mo, D. Z., \& Zhen, S. J. (2014). Poly(thieno[3,4-b]-1,4-oxathiane): medium effect on electropolymerization and electrochromic performance. Langmuir, 30(51), 15581-15589. http://dx.doi. org/10.1021/la503948f. PMid:25469424.

47. Lu, B. Y., Zhen, S. J., Zhang, S. M., Xu, J. K., \& Zhao, G. Q. (2014). Highly stable hybrid selenophene-3,4-ethylenedioxythiophene as electrically conducting and electrochromic polymers. Polymer Chemistry, 5(17), 4896-4908. http://dx.doi.org/10.1039/ C4PY00529E.

48. Ming, S. L., Zhen, S. J., Liu, X. M., Lin, K. W., Liu, H. T., Zhao, Y., Lu, B. Y., \& Xu, J. K. (2015). Chalcogenodiazolo [3,4-c]pyridine based donor-acceptor-donor polymers for green and nearinfrared electrochromics. Polymer Chemistry, 6(48), 8248-8258. http://dx.doi.org/10.1039/C5PY01321F.

49. Ming, S. L., Zhen, S. J., Lin, K. W., Zhao, L., Xu, J. K., \& Lu, B. Y. (2015). Thiadiazolo[3,4-c]pyridine as an acceptor toward fast-switching green donor-acceptor-type electrochromic polymer with low bandgap. ACS Applied Materials \& Interfaces, 7(21), 11089-11098. http://dx.doi.org/10.1021/acsami.5b01188. PMid:25955881.

50. Gu, H., Ming, S. L., Lin, K. W., Chen, S., Liu, X. M., Lu, B. Y., \& Xu, J. K. (2018). Isoindigo as an electron-deficient unit for high-performance polymeric electrochromics. Electrochimica Acta, 260, 772-782. http://dx.doi.org/10.1016/j. electacta.2017.12.033

51. Vorotyntsev, M. A., Deslouis, C., Musiani, M. M., Tribollet, B., \& Aoki, K. (1999). Transport across an electroactive polymer film in contact with media allowing both ionic and electronic interfacial exchange. Electrochimica Acta, 44(12), 2105-2115. http://dx.doi.org/10.1016/S0013-4686(98)00318-1.

52. Pajkossy, T., \& Kolb, D. M. (2007). Double layer capacitance of the platinum group metals in the double layer region. Electrochemistry Communications, 9(5), 1171-1174. http:// dx.doi.org/10.1016/j.elecom.2007.01.002.

53. Pajkossy, T., \& Kolb, D. M. (2001). Double layer capacitance of Pt(111) single crystal electrodes. Electrochimica Acta, 46(20-21), 3063-3071. http://dx.doi.org/10.1016/S00134686(01)00597-7.

Received: May 12, 2019

Revised: Feb. 27, 2020

Accepted: Mar. 04, 2020 


\section{Supplementary Material}

Supplementary material accompanies this paper.

Figure S1. Tauc curves for PEDOT (a), PEDOT-co-PPhTAc-2a (b), PEDOT-co-PPhTAc-2b (c), and PEDOT-co-PPhTCb (d). This material is available as part of the online article from http://www.scielo.br/po 